\title{
An observational study investigating the positioning of epidural catheters and their function during labour analgesia
}

\author{
Ellis Muggleton, Tülin Muggleton, Pawel Bergman \\ Department of Anesthesiology \& Intensive Care Medicine, Rotkreuzklinikum München \\ Ellis.muggleton@gmail.com
}

\section{SUMMARY}

- Carrying out of epidural anaesthesia involves an essentially blind insertion process

- This leads to inadequate analgesia in up to $25 \%$, failure to convert to surgical anaesthesia in up to $21 \%$.

- The exact reason for the failure is often not clear until catheter removal.

\section{Methods}

- Retrospective analysis of 48 epidural catheters for labour analgesia was carried out to determine the physical changes that had occurred.

- We questioned the women to correlate the catheter shape with its effectiveness.

- We recorded the angle that the catheter was bent in both a cephalic-caudal direction as well as a medial-lateral direction. Average position of the epidural tip as well as determined

Results

- Most common level of insertion was L3/4 (42/48)

- Average 1.17 attempts.

- Tip lay caudally to the insertion point in $10 \%$ of the patients $(5 / 48)$

- Mean tip position was practically central $(0.8 \mathrm{~cm}$ right of midline)

- Tip varied from $46 \mathrm{~mm}$ to the left of the midline to $32 \mathrm{~mm}$ to the right of the midline.

- Average distance from the midline was greater in patients with sensory disturbance versus those without (14.5mm vs. $2.6 \mathrm{~mm})$.

- Depth of the tip of the catheter correlated reasonably with the deviation from the midline $(R=$ 0,65 ) whilst, interestingly, the depth of LOR did not.

- Effectiveness: 6/48 inadequate analgesia (on average $12 \mathrm{~mm}$ from midline)

\section{Conclusion}

- Greater emphasis should be placed on positioning of the epidural

- Replacement when inadequate function

- Confirmation with Doppler/electrical stimulation? ${ }^{2}$

\section{Epidural Catheter Examples:}
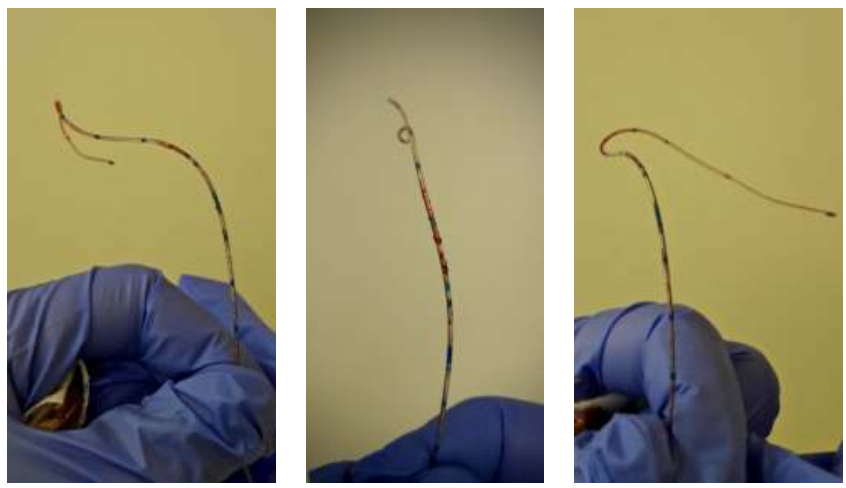

Back of Patient.

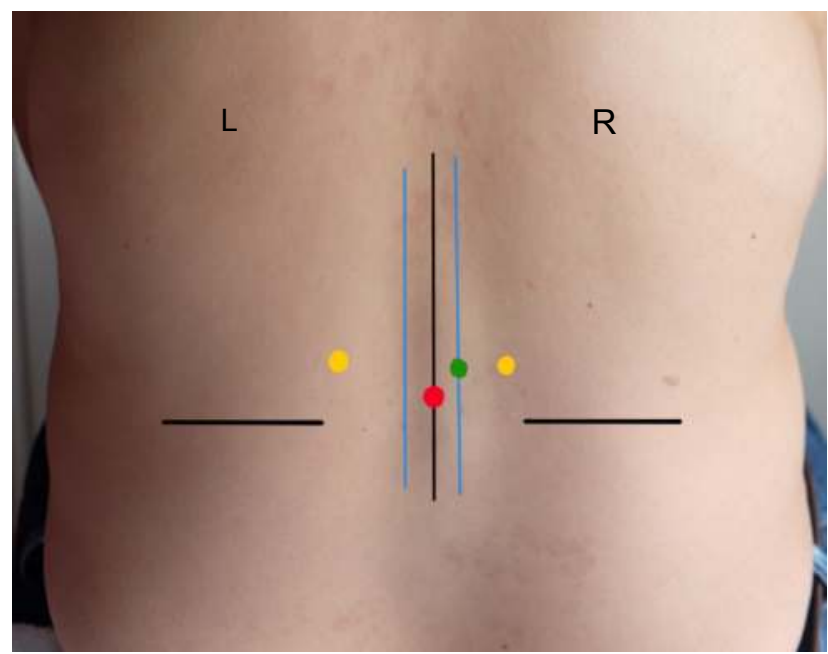

1. Hermanides J. Holmann MW, Stevens MF, Link P. Failed epidural: causes and management. Br J Anaesth. 2012 Aug: 109(2): 144-54.

2. Forester JG, Niemi TT, Salmenpera MT, Ikonen S, Rosenberg PH. An evaluation of the epidural catheter position by epidural nerve stimulation in conjunction with continuous epidural analgesia in adult surgical patients. Anaesth Analgesia. 2009 Jan: 108(1): 351-8. 